\title{
Efficient induction of spawning of Northern leopard frogs (Lithobates pipiens) during and outside the natural breeding season
}

Vance L Trudeau ${ }^{1 *}$, Frederick W Schueler ${ }^{2}$, Laia Navarro-Martin ${ }^{1}$, Christine K Hamilton ${ }^{1}$, Elizabeth Bulaeva ${ }^{1}$, Amanda Bennett ${ }^{3}$, William Fletcher ${ }^{1}$ and Lisa Taylor ${ }^{4}$

\begin{abstract}
Background: Amphibian declines are now recognized globally. It is also well known that many anurans do not reproduce easily in captivity, especially when held over long periods, or if they require hibernation before breeding. A simple method to induce spawning and subsequent development of large numbers of healthy tadpoles is therefore required to meet research and conservation goals.

Methods: The method is based on simultaneous injection of both female and male leopard frogs, Lithobates pipiens (formerly called Rana pipiens) with a cocktail of a gonadotropin-releasing hormone agonist (GnRH-A) and a dopamine antagonist. We call this the AMPHIPLEX method, which is derived from the combination of the words amphibian and amplexus. Following injection, the animals are thereby induced, and perform amplexus and natural fertilization under captive conditions.

Results: We tested combinations of a GnRH agonist with 2 different dopamine antagonists in L. pipiens in the breeding season. The combination of des-Gly ${ }^{10}$, D-Ala ${ }^{6}$, Pro-NHEt ${ }^{9}-G n R H(0.4$ micrograms/g body weight; GnRH-A) with metoclopramide hydrochloride (10 micrograms/g body weight; MET) or domperidone (DOM) were equally effective, producing $89 \%$ and $88 \%$ successful spawning, respectively. This yielded more than 44,000 eggs for the $16 / 18$ females that ovulated in the GnRH-A+MET group, and more than 39,000 eggs for the 15/17 females that ovulated in the GnRH-A+DOM group. We further tested the GnRH-A+MET in frogs collected in the wild in late autumn and hibernated for a short period under laboratory conditions, and report a low spawning success (43\%). However, GnRH-A priming 24 hours prior to injections of the GnRH-A+MET cocktail in animals hibernated for 5-6 weeks produced out-of-season spawning (89\%) and fertilization (85\%) comparable to those we observed for inseason spawning. Assessment of age and weight at metamorphosis indicated that L. pipiens tadpoles resulting from out-of-season spawning grew normally and metamorphosed successfully.
\end{abstract}

Conclusion: We provide evidence for successful captive breeding of the leopard frog, L. pipiens. This simple protocol can be used to obtain large numbers of eggs in a predictable, timed manner.

Keywords: Lithobates pipiens, Induced spawning, Leopard frogs, Hormone

\footnotetext{
* Correspondence: trudeauv@uottawa.ca

${ }^{1}$ Centre for Advanced Research in Environmental Genomics, Department of

Biology, University of Ottawa, Ottawa, Ontario K1N 6N5, Canada

Full list of author information is available at the end of the article
} 


\section{Background}

Global amphibian loss is considered a major factor in the contemporary "sixth mass extinction" according to Wake and Vreedenberg [1]. The potential detrimental ecological impacts have been discussed and debated extensively [1-5]. Perhaps $30 \%$ of known amphibians are endangered. Significantly, it was Nace [6] more than 40 years ago, who recognized that some populations of Lithobates pipiens (formerly Rana pipiens) in the U.S.A. were already declining in the mid-1960s. Today, Western North American populations, including those in Alberta, British Columbia, Colorado, and Nevada have dramatically declined [7-10]. Northeastern Ontario populations of L. pipiens have also been declining over the last 40 years [11].

Nace and colleagues $[6,12]$ were probably amongst the earliest to suggest the need for captive breeding and eventual domestication of frogs. Timed breeding in captivity is therefore a critical step for the propagation of any threatened or endangered species. To address this challenge, Nace et al. established the University of Michigan Amphibian Facility in the late 1960s [6,12]. They reported $[6,12]$ that spawning in captivity was possible but involved injections of pituitary extracts, which necessitates sacrifice of adult leopard frogs, thus defeating the main purpose of a captive colony of a species in decline. The costs, risks, inefficiencies and inappropriateness of injection of pituitary extracts have been discussed by Clulow et al. [13]. Unfortunately, the early attempts $[6,12]$ at induced breeding did not lead to establishment of a spawning method for captive leopard frogs. This was at a time before the discovery of the hypothalamic decapeptide gonadotropin-releasing hormone $(\mathrm{GnRH})$, and little was known about the neuronendocrine control of reproduction in frogs.

While it is now known that GnRH and GnRH agonist treatments can stimulate pituitary luteinizing hormone (LH) release in frogs $[14,15]$, they may not effectively induce spawning without co-treatments with other hormones or neuroactive agents [16-18]. This is indicative of the existence of an inhibitory neuroendocrine mechanism controlling the surge release of LH required for ovulation and spawning. Until recently, this possibility had not been considered important in frog reproduction despite clear but limited evidence to the contrary. Electrolytic lesions in the hypothalamus and infundibular regions of the hibernating frog Rana temporaria [19] increased GnRH and LH release and advanced spawning times, thereby establishing the existence of an LH-inhibitory system in the frog neuroendocrine brain. It is known that these brain areas contain the catecholamine dopamine (DA) [20] and DA type 2 receptors have been found in the frog pituitary $[21,22]$. Immunocytochemical visualization of DA neuronal fibres in the hypothalamus and median eminence of Rana ridibunda indicates that DA can be delivered to the pituitary [23]. The DA agonist bromocriptine can inhibit LH release and ovulation in $R$. temporaria in some situations [24]. Moreover, long-term implantation of silastic pellets containing the DA antagonist metoclopromide (MET) induced ovulation in hibernating $R$. temporaria [24]. These data indicate that DA is an important inhibitor of LH release in frogs as it is in numerous fish species, birds and some mammals, including sheep and humans [25]. Browne et al. [18] explored the effects of combinations of hormones on spawning in Bufo fowlerii. In that study, they used the DA antagonist pimozide and concluded that pimozide may increase spawning in some situations and hormone combinations. However, pimozide is not specific to DA receptors, and acts on adrenergic and serotoninergic receptors in addition to DA receptors [26], so it's use should be avoided. Nevertheless, together these studies led us to test several dopamine antagonists in L. pipiens.

In our first report on hormonal induction of spawning in L. pipiens, it was clear that the combination of des$\mathrm{Gly}^{10}$, D-Ala ${ }^{6}$, Pro-NHEt ${ }^{9}-\mathrm{GnRH}$ (GnRH-A) and the specfic DA D2-receptor antagonist MET gave the best results. We named the approach the AMPHIPLEX method, a term that derives from the combination of the words amphibian and amplexus. Amplexus refers to the specific reproductive behaviour of frogs where the male grasps the female, helping to stimulate ovulation and after some delay fertilizes the eggs as they are laid. In one year in the breeding season, we obtained fertilized egg masses from 100\% of females, while in the second year this was only 60\% [27]. We considered these in-season spawning results for L. pipiens a good first step [27]. On the other hand, out-of-season breeding success was very low in $L$. pipiens [27], indicating that significant improvements are needed.

Here we report on the efficient, large-scale spawning induction during the reproductive season of L. pipiens following co-injection of GnRH-A and either of the DA antagonists MET or domperidone. Given the efficacy and ease of use of the GnRH-A+MET combination, we also successfully induced breeding out-of season and obtained thousands of viable tadpoles. In our case, the main reason for this planned breeding is to obtain healthy tadpoles in a timed manner for physiological, ecotoxicological and epidemiological studies [28,29]. In the long-term our goal is to establish captive colonies so that harvesting of wild eggs can be stopped because the iconic North American frog L. pipiens is unfortunately in decline in several regions of the traditional range [7-12]. 


\section{Methods \\ Experiment 1: Large-scale induction of spawning in the spring breeding season of $L$. pipiens}

Mature leopard frogs (51 females, 81 males) were collected near Bishops Mills, Ontario during their spring migration to breeding pools between April 9 and 13, 2011. The animals were kept cold $\left(4^{\circ} \mathrm{C}\right)$ temporarily and were transported on April 19 (water temperature 6-7 ${ }^{\circ} \mathrm{C}$ ) to the National Wildlife Research Centre, Ottawa and housed outside in large $380 \mathrm{~L}$ high-density polyethylene (Rubbermaid) tanks containing $200 \mathrm{~L}$ of water as described previously [27]. The sexes were housed separately and acclimated to the tanks until injection. Typically, 2 mature females and 3 mature males were placed in each tank with submerged branches as spawning substrate. Mean $( \pm$ SD) body weights for all females and males used in this experiment were respectively $51.1 \pm$ 7.6 and $29.5 \pm 6.2$ g. Each breeding tank was only observed once per day at the time when water temperatures were recorded in the morning. Water temperature in the tanks varied between $12-16^{\circ} \mathrm{C}$ at the time of injection (Day 1) and respectively $13-17^{\circ} \mathrm{C}$, $11-12^{\circ} \mathrm{C}$, and $9-11^{\circ} \mathrm{C}$ on Day 2,3 and 4 . Thereafter, tank temperatures were $15-16^{\circ} \mathrm{C}$.

Animals were injected between 12:00-17:00 h on April 30, 2011. Animals in the control group (16 females and 27 males) were injected intraperitoneally (i.p.) with saline $(0.7 \% \mathrm{NaCl} ; 1 \mu \mathrm{l} / \mathrm{g})$ and $\operatorname{DMSO}(1 \mu \mathrm{l} / \mathrm{g})$ vehicles using a 26-gauge needle attached to a disposable 1-ml syringe. The AMPHIPLEX method is based on injections of a mixture of des-Gly ${ }^{10}$, D-Ala ${ }^{6}$, Pro-NHEt ${ }^{9}-\mathrm{GnRH}$ (Bachem H4070; $0.4 \mu \mathrm{g} / \mathrm{g}$ body weight (BW); GnRH-A) and metoclopramide (Sigma M0763; $10 \mu \mathrm{g} / \mathrm{g}$ BW; MET) as reported previously [27] except that both GnRH-A and MET were dissolved together in saline. These animals were also injected with DMSO control $(1 \mu \mathrm{l} / \mathrm{g})$ to be comparable to the other groups. There were 18 females and 27 males in the GnRH-A+MET treatment group. We also wanted to test another dopamine antagonist, therefore, a third group was treated with GnRH-A $(0.4 \mu \mathrm{g} / \mathrm{g}$ body weight; GnRH-A) and domperidone (generous gift from Janssen Pharmaceutica; $10 \mu \mathrm{g} / \mathrm{g} \mathrm{BW}$; DOM). It was necessary to dissolve DOM in DMSO because it is not soluble in water. There were 17 females and 27 males in the GnRH-A+ DOM group.

On Day 5 post-injection, the resulting egg masses were weighed and placed in individual aquaria at room temperature $\left(21^{\circ} \mathrm{C}\right)$ to observe and record embryonic development. Post-spawning body weight of females was also recorded. Additionally, 3 small subsamples of the egg masses were weighed and the number of eggs counted under a dissection microscope. The average number of eggs per gram of subsample was multiplied by total egg mass weight to estimate total fecundity.
Relative fecundity was estimated by dividing the total number of eggs by the pre-spawning body weight of females. Percent fertilization rates were estimated by determining the proportion of developing and nondeveloping embryos 4 days following spawning.

It should be noted that the females that did not spawn were sacrificed and it was determined that they did have eggs.

\section{Experiment 2: Out of season induction of spawning of $L$. pipiens in captivity}

For the breeding trials that occurred outside the normal spring breeding season, mature leopard frogs were collected near Bishops Mills, Ontario from mid November-early December 2011 using submerged minnow traps in a deep pond, which is a traditional, successful hibernation site for leopard frogs in this region. The animals were kept cold $\left(4^{\circ} \mathrm{C}\right)$ temporarily and were transported and housed in-doors in tanks at $4^{\circ} \mathrm{C}$ at the University of Ottawa aquatic facility. Mean ( \pm SD) body weights for all females and males used in this experiment were respectively $51.9 \pm 8.5$ and $25.5 \pm 6.6$ g. Two trials were conducted.

In the first trial, 7 females and 7 males were placed separately in breeding tanks (internal diameter $0.9 \mathrm{~m}$, depth $0.36 \mathrm{~m}$, total volume of 230 litres) and maintained at $4-6^{\circ} \mathrm{C}$, in the dark for 23 days. Thereafter they were exposed to $6 \mathrm{~h}$ light (14:00-20:00h; 100W Phillips Natural Light bulb, 1200 lumens) for one day, then 14h light (06:00-20:00h for the remainder of the experimental period. The temperature was gradually increased to $16-17^{\circ} \mathrm{C}$ over 6 days, starting on the same day that lights were turned on. The following day, animals were injected i.p. in the afternoon with GnRH-A+MET. Four females with 4 males were placed in one tank, and 3 females with 3 males were placed in another tank.

For the second trial, we set out to improve spawning success using a priming pre-treatment with a low dose of GnRH-A before injection with GnRH-A+MET. Twelve females and 16 males were kept separately in holding tanks (internal diameter is about $0.67 \mathrm{~m}$, depth about $0.33 \mathrm{~m}$, total volume of $115 \mathrm{l}$ ) and maintained at 4- $6^{\circ} \mathrm{C}$, in the dark for $5-8$ weeks. Thereafter, they were exposed to the same photoperiod/temperature regimen described above for Trial 1. For the priming pretreatment, females and males were injected i.p. between 14:00-14:30 with a low dose of GnRH-A (0.04 mg/g; Day 1). Animals were moved to the breeding tanks but the sexes were kept separated. Twenty-four hours later (Day 2), animals were injected i.p. with GnRH-A+MET. Immediately following this injection, 3 females and 4 males were placed in a given breeding tank $\left(16-17^{\circ} \mathrm{C}\right)$.

For both trials in Experiment 2, the resulting egg masses were weighed and the post-spawning body weight 
recorded. Fertilization and fecundity measurements followed the protocol described for Experiment 1.

The females that did not spawn were sacrificed and it was determined that they did have eggs.

\section{Experiment 3: Development and survival of tadpoles generated from out-of-season breedings}

Three egg masses obtained from pairs injected only with GnRH-A+MET (masses 1-3) and 2 egg masses from the GnRH-A priming protocol (masses 4-5) were further assessed. These 5 egg masses were studied to determine tadpole survival, growth, and metamorphic rates in addition to potential genetic (parental) influences on these parameters. Five fertilized egg masses were removed from the breeding tanks from the out-of-season breeding trials reported above and placed individually in $20 \mathrm{~L}$ glass tanks at room temperature until hatching and development to Gosner Stage (Gs) 25. [30]. Percent fertilization estimates for these eggs masses varied between 10 and 92.7\%. The tadpoles were reared in a Tecniplast-ZebTec recirculating system, starting with addition of Gs25 tadpoles. The water was maintained at a constant temperature $\left(21^{\circ} \mathrm{C}\right), \mathrm{pH}(7.4)$, and conductivity $(\sim 1000 \mu S)$. Tadpoles were initially stocked at a density of approximately 2 tadpoles/L of water (e.g., 15 tadpoles per 8L ZebTec tank), and this was not adjusted as the tadpoles developed. There were 5 replicate tanks for each egg mass. Tadpoles were fed commercial rabbit pellets ad libidum. Excess food was removed daily.

At approximately Gs40, a floating Styrofoam plate and plastic grill was placed in each tank so that tadpoles could rest, and prepare to leave the water at metamorphosis. To reduce the chance of drowning, upon reaching Gs45 froglets were transferred to $100 \times 15 \mathrm{~mm}$ glass Petri dishes with $5 \mathrm{ml}$ water. Once metamorphosis was completed (Gs46, complete tail regression), animals were anaesthetised in tricaine-methanesulfate (MS-222, Sigma) and sacrificed.

For each metamorph, the snout-vent length (SVL; precision, $0.1 \mathrm{~mm}$ ), weight (W; precision, $0.1 \mathrm{mg}$ ), type and incidence of deformities, and total days post-fertilization to complete metamorphosis (DTM) were recorded. The condition factor $(\mathrm{k})$ was calculated using SVL and weight measurements as follows: $\mathrm{k}=\left(\mathrm{W}(\mathrm{g}) / \mathrm{SVL}\left(\mathrm{cm}^{3}\right) * 100\right.$. Survival at Gs45 was calculated by comparing the number of tadpoles reaching that stage with the total number of Gs25 embryos at the beginning of the experiment. The percentage of Gs 25 embryos that completed metamorphosis (Gs46) was also determined.

\section{Statistical analyses}

Online freeware was used for statistical analysis of spawning induction data. Fisher's Exact test (www. graphpad.com) and Student's T-test (http://studentsttest. com) were used. Data are reported as mean \pm SD.

For the data on tadpole development, growth and survival, the statistical analyses were performed using SPSS version 15.0 (Chicago, Illnois, USA). Normality was verified using Shapiro-Wilks' test and logarithmic transformations were performed to ensure normality when required. Homoscedasticity of variances was verified with Levene's test. A one-way analysis of variance (ANOVA) was used to test for statistical differences between egg masses in SVL, W, K and DTM. Differences in percentage of animals that complete metamorphosis, incidence of malformations, survival to Gs45 and death rate between Gs45 and Gs46 were determined using the non-parametric test Krustal-Wallis. Data are expressed as mean $\pm \mathrm{SD}$. In all tests, differences were accepted as significant when $\mathrm{p}<0.05$.

All procedures followed the animal care guidelines of the University of Ottawa and the Canadian Council on Animal Care.

\section{Results}

Experiment 1: Large-scale induction of spawning in the spring breeding season of $L$. pipiens

One pair of saline-injected control animals was observed in amplexus on Day 3 This couple remained in amplexus for 2 days but did not spawn.

In the treated groups, the first egg masses were seen on Day 3. On Day 3, 5/18 pairs were in amplexus and 2 egg masses were laid in the GnRH-A+MET group. On Day 3, 9/17 pairs were in amplexus and one egg mass was laid in the GnRH-A+DOM group. By Day 5, spawning activity stopped. Regardless of treatment, all egg masses laid were fertilized $(>90 \%)$ and led to development of healthy tadpoles. In the GnRH-A+MET group 16/18 (89\%) females laid eggs. In the GnRH-A+DOM group 15/17 (88\%) females laid eggs (see Table 1). There was no difference in the proportion of females laying eggs in the GnRH-A+MET and GnRH-A+DOM groups $(\mathrm{p}=1.00$, Fisher's Exact test).

The body weight loss in females after spawning was on average $20.0 \%$ (range 11.3-35.4\%) in the GnRH-A+MET group and $20.3 \%$ (range 10.2-35.1\%) in GnRH-A+DOM group ( $p>0.05$; T-test). Total egg mass weight was also not different ( $>0.05$; T-test) between the treatment groups and was $137.4 \pm 34.5 \mathrm{~g}$ for $\mathrm{GnRH}-\mathrm{A}+\mathrm{MET}$ and $130.3 \pm 27.2 \mathrm{~g}$ for GnRH-A+DOM. Similarly, the total number of eggs per egg mass were not different $(p>0.05$; T-test) between the treatments and were $2764 \pm 690$ and $2642 \pm 597$ for GnRH-A+MET and GnRH-A+DOM, respectively (Table 1). One estimate of fecundity is eggs per gram pre-spawning body weight. This was estimated to be $54 \pm 10$ and $54 \pm 12$ for the GnRH-A+MET and GnRH-A+DOM groups, respectively, which were not 
Table 1 Spawning success in a large-scale in-season breeding trial in Spring 2011

\begin{tabular}{lcccc}
\hline Spawning in L. pipiens & Egg masses (\%) & \#eggs/female & Relative fecundity (\#eggs/g BW) & Total \# eggs collected \\
\hline Control & $0 / 16(0)$ & 0 & 0 & 0 \\
GnRH-A+MET & $16 / 18(89)^{* * * *}$ & $2764 \pm 690^{\text {ns }}$ & $54 \pm 10^{\text {ns }}$ & 44,224 \\
GnRH-A+DOM & $15 / 17(88)^{* * * *}$ & $2642 \pm 597^{\text {ns }}$ & $54 \pm 12^{\text {ns }}$ & 39,630 \\
\hline
\end{tabular}

Data were analysed with Fisher's Exact Test (egg masses; $\left.{ }^{* * *} \mathrm{p}=0.0001\right)$, and T- Test (GnRH-A+MET vs. GnRH-A+DOM; (\# eggs per female and relative fecundity; ns, $\mathrm{p}>0.05$ ). The total number of eggs obtained per treatment was estimated (\# females that spawned $\mathrm{x}$ \#eggs/ female). See Methods for details on experimental protocols.

significantly different $(\mathrm{p}>0.05)$. We obtained approximately 44,224 eggs for the 16 females that ovulated in the GnRH-A+MET group. For the GnRH-A+DOM group we obtained approximately 39,630 eggs for the 15 females that ovulated.

\section{Experiment 2: Induction of spawning of $L$. pipiens in captivity in winter outside of the normal spring breeding season}

Data from this experiment is shown in Table 2. In Trial 1 of Experiment 2 without GnRH-A priming, 3/7 (43\%) females treated with GnRH-A+MET laid eggs. The first egg mass was laid on Day 2, and the others on Day 4. All 3 egg masses were fertilized (range 10- 81\%). At the end of the trial, the females were sacrificed. There were virtually no eggs left in the females that spawned but the 4 others were full of eggs that were not released.

In Trial 2 of Experiment 2 with GnRH-A priming (Table 2), 11/12 (92\%) females treated with GnRH-A+MET laid eggs, which was a significant improvement in spawning rate compared to Trial $1(\mathrm{p}=0.0001$; Fisher's Exact test). On Day 3, which was 1 day after injection with GnRH-A+MET, 5/12 couples were in amplexus. On day 4, 6 other couples were in amplexus. The first egg masses (4/12) were also observed on Day 4. By Day 5, 11/12 females laid eggs. No other spawning activity was observed after Day 5.

Total egg mass weight was $127.5 \pm 55.6 \mathrm{~g}$ in Trial 1 and $132.4 \pm 59.4 \mathrm{~g}$ in Trail 2 and was not significantly different ( $\mathrm{p}=0.90$; T-test). The total number of eggs per egg mass was 2,052 \pm 871 in Trial 1 and 1,584 \pm 777 in Trial 2 ( $\mathrm{p}=0.46 ; \mathrm{T}$-test). Relative fecundity as indicated by eggs per gram pre-spawning body weight was estimated as $36 \pm 15$ and $31 \pm 14$ for Trial 1 and Trial 2, respectively ( $\mathrm{p}=0.69 ; \mathrm{T}$-test). We recorded high \% fertilization levels in Trial 2 of Experiment 2. On average

Table 2 Spawning success in out-of season breeding trials (Winter 2011-2012)

\begin{tabular}{lcc}
\hline Spawning in L. pipiens & Egg masses (\%) & \%Fert \\
\hline Trial 1 - GnRH-A+MET & $3 / 7(43)$ & $47 \pm 35$ \\
Trial 2 - GnRH-A priming, GnRH-A+MET & $11 / 12(92)^{* * * *}$ & $85 \pm 15^{*}$ \\
\hline
\end{tabular}

Data were analysed with Fisher's Exact test (Egg Masses; $\left.{ }^{* * *} \mathrm{p}=0.0001\right)$ and TTest (\% Fert; percent fertilization, ${ }^{*} p=0.046$ ). See Methods for details on the 2 trials. this was $85 \%$ (range $53-98 \%$ ) and was significantly higher ( $\mathrm{p}=0.046$; $\mathrm{T}$-test) than fertilization estimates obtained in Trial 1 (Table 2).

The average body weight for in-season females that laid eggs was $51.1 \pm 7.6 \mathrm{~g}$ and was not different from the average body weight of $51.9 \pm 8.5 \mathrm{~g}$ for all out-of season females that laid eggs. Similarly, average weight of egg masses per female was also not different ( $\mathrm{p}>0.05$; T-test; see Table 3). The total number of eggs laid per female was significantly lower by $43 \%$ in the out-of-season spawnings compared to the in-season spawnings $(\mathrm{p}<0.0005)$. The average number of eggs per gram body weight was $54 \pm 10$ for the females from the spring 2011 breeding season treated with GnRH-A+MET. In contrast the average number of eggs per gram body weight for females primed with GnRH-A, then injected with GnRH-A+MET in the out-of-season breeding trial was $31 \pm 14$, which was $43 \%$ lower $(\mathrm{p}=0.00009$; $\mathrm{T}$-test $)$.

\section{Experiment 3: Development and survival of tadpoles generated from out-of-season breedings}

After hatching, Gs25 tadpoles were raised to metamorphosis. The average time to metamorphosis ranged from 85.0 to 118.8 days, and is significantly different between some of the egg masses (Table 4). There were 5 replicate tanks for each of these 5 egg masses. Overall, the average $\%$ of individuals reaching metamorphosis was $74.1 \pm$ 16.5. Individually, egg masses $1,2,3$ and 4 were very similar with $80.0 \pm 13.3,82.7 \pm 13.8,77.3 \pm 11.2$ and 81.3 $\pm 9.9 \%$ of animals completing metamorphosis, respectively. Examples of normal tadpoles and metamorphs from the out-of-season breeding are shown in Additional file 1: Figure S1. The dominant malformation in tadpoles was spinal curvature, and the average was $8 \%$ for the entire population of tadpoles studied. Most of these were observed for one egg mass. The incidence of abnormalities was $0,1.4,3.1,0$ and $35.5 \%$ in egg masses $1,2,3,4$ and 5 , respectively. Egg mass 5 was significantly different ( $p<0.05$ ) from the others, with $49.3 \pm 7.6 \%$ reaching metamorphosis. It was also egg mass 5 that had the lowest survival, shortest time to metamorphosis, and the highest incidence of malformations. While the higher mortality and abnormalities are likely related to the genetic background of the parents, the bigger size and increased condition factor of the tadpoles from 
Table 3 Comparison of fecundity in eggs obtained from the in-season and out-of-season spawnings

\begin{tabular}{lccc}
\hline Spawning in L. pipiems & Weight of Egg masses (g) & \# Eggs/female & Relative fecundity (\#eggs/g BW) \\
\hline $\begin{array}{l}\text { In season } \\
\text { (no priming, GnRH-A+MET) }\end{array}$ & $135 \pm 6$ & $2744 \pm 118$ & $54 \pm 10$ \\
$\begin{array}{l}\text { Out of season } \\
\text { (GnRH-A priming, GnRH-A+MET) }\end{array}$ & $131 \pm 15$ & $1584 \pm 234^{* * *}$ & $31 \pm 4^{*}$ \\
\hline
\end{tabular}

Data were analysed with T- Test $\left.{ }^{* * *} \mathrm{p}<0.0005 ;{ }^{*} \mathrm{p}<0.05\right)$. Please see Methods for detailed description of the experiments.

egg mass 5 most probably relates to rearing conditions. We did not adjust tadpole densities during development to adjust for the different rates of mortality. Regardless, it is clear that there are differences between the breeding couples in captivity that reflect typical variations in natural populations.

\section{Discussion}

We report on the efficient hormonal induction of spawning in the Northern leopard frog, L. pipiens. This simple protocol can be used to obtain large numbers of eggs for in-season and out-of-season breeding.

In our first study on hormonally-induced spawning in anurans [27] we tested 2 different DA antagonists, pimozide and MET, in combination with several GnRH agonists. From those early results it was clear that MET was more effective than pimozide. In the natural spring breeding season in the current study, none of the control animals laid eggs, consistent with previous observations for L. pipiens under the captive conditions in outdoor breeding tanks [27]. In marked contrast, 89 and $88 \%$ of female in the GnRH-A+MET and GnRH-A + DOM treatment groups, respectively, laid eggs that were all fertilized by the males. The well-characterized DA D2-type receptor antagonist MET is water-soluble and readily crosses the blood-brain barrier. The site of action of MET to antagonize DA receptors and promote successful spawning may therefore be at both the level of the brain and pituitary. Domperidone is also a wellcharacterized DA D2 receptor antagonist that is not water-soluble and does not cross the blood-brain barrier [31]. Therefore the antagonism of DA D2 receptors by DOM that leads to potentiation of GnRH action on $\mathrm{LH}$ release and induction of spawning is at the level of the pituitary [22,31]. Regardless, both formulations effectively induced spawning in $L$. pipiens in the breeding season. In only 4 days were able to harvest nearly 84,000 eggs from the 31 females that successfully laid eggs. Based on our results, we recommend the mixture of GnRH-A+MET over GnRH-A+DOM because of the ease of preparation and use.

We sought to further test GnRH-A+MET for out-of -season breeding under laboratory conditions. Firstly, we obtained only 3 fertilized egg masses from 7 females and 7 males collected in mid-November and injected with GnRH-A+MET in mid-December after being kept for approximately 1 month in the laboratory. The important innovation we report here is the improved out-of-season breeding outcomes. It is clear that a single injection of GnRH-A+MET works well with animals that are sexually mature in the natural breeding season. We reasoned that part of the initial low success out-of-season related to either reduced pituitary sensitivity to $\mathrm{GnRH}$, and/or to reduced stores of gonadotropins in the pituitary. Both possibilities are well-documented in seasonally breeding poikilotherms, for example, in goldfish [32,33]. Therefore, we used the principle of $\mathrm{GnRH}$ priming to enhance the response of gonadotrophs in the anterior pituitary to subsequent $\mathrm{GnRH}$ treatment. It is well-known that $\mathrm{GnRH}$ can upregulate $\mathrm{GnRH}$ receptor numbers and LH production in the vertebrate pituitary by a mechanism called GnRH self-priming [15,34,35]. Therefore, in the present study we gave $10 \%$ of the GnRH-A dose $(0.04 \mu \mathrm{g} / \mathrm{g} \mathrm{BW})$ in GnRH-A+MET as a priming dose to both males and females. This was followed $24 \mathrm{~h}$ later by GnRH-A+MET, a mixture of the same GnRH-A and the DA antagonist

Table 4 Characteristics of metamorphosed froglets from 5 different parental pairs

\begin{tabular}{cccccc}
\hline Egg mass (\%Fert) & N (\%) & DTM & W (g) & SVL (cm) & k \\
\hline $\mathbf{1}(47.6)$ & $63(84 \%)$ & $105.2 \pm 25.3^{\mathrm{b}}$ & $0.86 \pm 0.23^{\mathrm{ab}}$ & $0.021 \pm 0.002^{\mathrm{a}}$ & $8.9 \pm 1.0^{\mathrm{a}}$ \\
$\mathbf{2}(10.0)$ & $64(85 \%)$ & $118.8 \pm 26.1^{\mathrm{c}}$ & $0.83 \pm 0.20^{\mathrm{a}}$ & $0.021 \pm 0.002^{\mathrm{a}}$ & $8.7 \pm 1.0^{\mathrm{a}}$ \\
$\mathbf{3}(92.7)$ & $61(81 \%)$ & $108.7 \pm 21.4^{\mathrm{bc}}$ & $0.88 \pm 0.21^{\mathrm{ab}}$ & $0.021 \pm 0.002^{\mathrm{a}}$ & $9.3 \pm 1.7^{\mathrm{ab}}$ \\
$\mathbf{4}(53.5)$ & $62(83 \%)$ & $105.0 \pm 29.2^{\mathrm{b}}$ & $1.04 \pm 0.26^{\mathrm{c}}$ & $0.023 \pm 0.002^{\mathrm{b}}$ & $8.6 \pm 0.8^{\mathrm{a}}$ \\
$\mathbf{5}(88.2)$ & $39(52 \%)$ & $85.0 \pm 17.9^{\mathrm{a}}$ & $0.95 \pm 0.19^{\mathrm{bc}}$ & $0.021 \pm 0.002^{\mathrm{a}}$ & $9.6 \pm 2.4^{\mathrm{b}}$
\end{tabular}

Data ( \pm SD) for days to complete metamorphosis (DTM), snout-vent length (SVL), weight (W) and condition factor (k) for each egg mass (1-5) is shown. Means that are significantly different are indicated by different letters $(p<0.05)$. Abbreviations: $N$, total number out of 75 Gosner Stage 25 embryos in the group that survived to metamorphosis (\% survival is shown in parentheses), DTM, days to metamorphosis; SVL, snout-vent length; W, weight; $\mathrm{k}$, condition factor; \%Fert, percent fertilization. 
MET. We report that $11 / 12$ females laid eggs with a very high level of fertilization. The out-of-season percent fertilization estimates in the primed group were on average $85 \%$, which is similar to fertilization rates $(>90 \%)$ in leopard frogs caught and induced with GnRH-A+MET only in the natural breeding period. Additionally, in another study a priming injection of the $\mathrm{GnRH}$ agonist Leuprorelin (pHis-Trp-Ser-Tyr-D-Leu-Leu-Arg-Pro-NHEt) improved Leuprorelin-induced spermiation and ovulation in Günther's toadlet, Pseudophryne guentheri; subsequent in vitro fertilization rates were very high [36]. These results indicates important advantages of $\mathrm{GnRH}$ priming in anurans.

The female $L$. pipiens that were induced to spawn in the natural breeding period and out-of-season had similar body sizes and similar egg mass weights. However, there was a difference in the number of eggs produced. The females in the natural breeding season produced on average $\sim 2,764$ eggs, whereas those out-of-season females produced only 1584 eggs. While these levels of egg production are within the normal but variable numbers for $L$. pipiens (800-7,500 per female [37]), there are several plausible explanations for this difference. The group of females caught in mid-November to early December 2011 may simply have had fewer developed eggs than those collected the previous spring in 2011. This could be natural variation from one cohort to another that would depend on nutritional conditions in the spring an summer following the breeding season. There were virtually no eggs remaining in the body cavity of those injected females that spawned, so partial release of the eggs cannot be the reason for differences in the number of eggs laid. Alternatively, it is possible that the relatively short period the out-of-season animals spend in cold-water conditions that simulated winter water temperatures was not enough to allow full ovarian development [38]. It will be important to determine the environmental and nutritional conditions to maximize egg numbers for out-of-season induced spawning in captive L. pipiens.

Another important consideration addressed in our study is the development of tadpoles obtained from captive breeding outside of the normal reproductive period. Generation of tadpoles for physiological and ecotoxicological experiments, and for captive breeding and reintroduction programs of endangered species all require large numbers of normal healthy tadpoles that grow and metamorphose. An additional requirement for reintroduction programs is the maintenance of genetic diversity, and therefore, careful management of broodstock and their offspring. We studied the 3 egg masses obtained from pairs injected only with GnRH-A+MET (masses 1-3) and 2 egg masses obtained from the GnRH-A priming protocol (masses 4-5). Levels of fertilization varied from $10-97.2 \%$, but the variations in developmental parameters measured were not related to this fertility estimate. The number of days from fertilization to metamorphosis (DTM) varied from $85-118$, which is well within the wide range (7-42 weeks) found in the literature [27,39-41]. Such variations reflect the extreme developmental plasticity and response to variable environmental conditions typical of anurans tadpoles [42]. Weight at metamorphosis was generally between 0.8 and $1.0 \mathrm{~g}$, similar to previous reports for eggs obtained in the wild but raised outdoor in mesocosms [41], but somewhat smaller than what we previously reported for tadpoles obtained from captive breeding [27], reflecting potential genetic differences in the parents, and/or the different rearing conditions. Tadpoles from egg mass 5 were the only group that was obviously different from the others. Tadpoles from egg mass 5 metamorphosed quicker, despite having higher mortality, higher incidence of abnormalities and many fewer that actually reached metamorphosis. The higher mortality and abnormalities are likely related to the genetics of the parents but we cannot attribute this to a female-based or a male-based effect. We do not have any other data from these parents since they have only been bred once. The metamorphs from egg mass 5 had a higher condition factor relative to the other 4 cohorts. Their bigger size and increased condition factor in likely related to rearing conditions. We did not adjust tadpole densities during development to compensate for the different rates of mortality. Regardless, it is clear that there are differences between the breeding couples in captivity that reflect typical variations in natural populations.

\section{Conclusions}

We provide evidence for successful captive breeding of the leopard frog, L. pipiens. This species may serve as a good model to use for the further development of robust spawning induction methods for endangered anurans because until now it has been considered very difficult to breed in captivity. The AMPHIPLEX method to inject both sexes simultaneously with a solution containing a GnRH agonist and a DA antagonist has been used successfully in 6 anuran species $[27,43,44]$.

\section{Additional file}

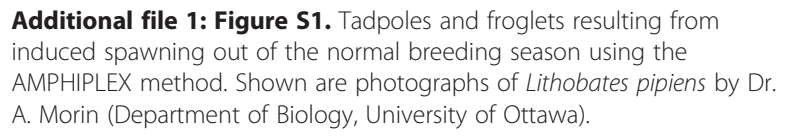

Competing interests

The authors declare that they have no competing interests. 


\section{Authors' contributions}

VLT developed the spawning induction method, designed, performed all breeding experiments with $L$. pipiens and wrote the paper. FS collected all $L$ pipiens and contributed to development of spawning conditions required. LNM and CKM designed and conducted the developmental studies. EB and $\mathrm{BF}$ contributed to the feeding, maintenance and hibernation protocols. $\mathrm{AB}$ performed some of the fertility studies. LT contributed to the design of the out-of-season breeding and tadpole maintenance protocols. All authors read and approved the final manuscript.

\section{Acknowledgements}

Aleta Karstad assisted with spring collections. We thank the Scott family of Lilliput Farm for access to their irrigation pond for the trapping of the autumnal samples. The authors acknowledge with appreciation the help of Lesley-Anne Howes with injections. The authors thank Antoine Morin for the photos of $L$. pipiens tadpoles and metamorphs. The financial support of Environment Canada (VLT, LT) and the University of Ottawa Research Chair Program (VLT) is acknowledged with appreciation.

\section{Author details}

Centre for Advanced Research in Environmental Genomics, Department of Biology, University of Ottawa, Ottawa, Ontario K1N 6N5, Canada. ${ }^{2}$ Bishops Mills Natural History Centre, Bishops Mills, Ontario KOG 1T0, Canada. ${ }^{3}$ Department of Biology, Trent University, Peterborough, Ontario K9J 7B8, Canada. ${ }^{4}$ Method Development and Applications Unit, Biological Assessment \& Standardization Section, Environment Canada, 335 River Road, Ottawa, Ontario K1A OH3, Canada.

Received: 14 October 2012 Accepted: 18 February 2013 Published: 25 February 2013

\section{References}

1. Wake DB, Vredenburg VT: Colloquium paper: are we in the midst of the sixth mass extinction? A view from the world of amphibians. Proc Natl Acad Sci USA 2008, 105(1):11466-11473.

2. Alford RA, Dixon PM, Pechmann JH: Ecology. Global amphibian population declines. Nature 2001, 412(6846):499-500.

3. Houlahan JE, Findlay CS, Schmidt BR, Meyer AH, Kuzmin SL: Quantitative evidence for global amphibian population declines. Nature 2000, 404(6779):752-755.

4. Stuart SN, Chanson JS, Cox NA, Young BE, Rodrigues AS, Fischman DL, Waller RW: Status and trends of amphibian declines and extinctions worldwide. Science 2004, 306(5702):1783-1786.

5. Krest $\mathrm{S}$, Linder G, Sparling D: The role of multiple stressor causes in declining amphibian populations: A wingspread workshop summary. ASTM Special Technical Publication 2003, :207-218.

6. Nace GW: The Amphibian Facility of the University of Michigan. BioScience 1968, 18(8):767-775.

7. Committee on the Status of endangered Wildlife in Canada (COSEWIC): Lithobates Pipiens, Rocky Mountain population, western Boreal/Prairie populations and Eastern population, in Canada. In COSEWIC assessment and update status report on the Northern Leopard Frog. 2009. http://www. sararegistry.gc.ca/species/speciesDetails_e.cfm?sid=552. vii +69 .

8. Hammerson G, Solís F, Ibáñez R, Jaramillo C, Fuenmayor Q: Lithobates pipiens. In: IUCN, IUCN Red List of Threatened Species. Version 2012.2 2012. (January 2013). www.iucnredlist.org >. Downloaded on 30.

9. Rogers SD, Peacock MM: The disappearing northern leopard frog (Lithobates pipiens): conservation genetics and implications for remnant populations in western Nevada. Ecol Evol 2012, 2(8):2040-2056.

10. Johnson PT, McKenzie VJ, Peterson AC, Kerby JL, Brown J, Blaustein AR, Jackson T: Regional decline of an iconic amphibian associated with elevation, land-use change, and invasive species. Conserv Biol 2011, 25(3):556-566.

11. Desroches J-F, Schueler F, Picard I, Gagnon L: A herpetological survey of the James Bay Area of Québec and Ontario. The Canadian Field-Naturalist 2010, 24:299-315.

12. Gibbs EL, Nace GW, Emmons MB: The live frog is almost dead. BioScience 1971, $21(20): 1027$.

13. Clulow J, Clulow S, Guo J, French AJ, Mahony MJ, Archer M: Optimisation of an oviposition protocol employing human chorionic and pregnant mare serum gonadotropins in the Barred Frog Mixophyes fasciolatus (Myobatrachidae). Reprod Biol Endocrinol 2012, 10(1):60.

14. Licht P, McCreery BR, Barnes R: Relation between acute pituitary responsiveness to gonadotropin releasing hormone $(\mathrm{GnRH})$ and the ovarian cycle in the bullfrog, Rana catesbeiana. Gen Comp Endocrinol 1983, 51(1):148-153.

15. Porter DA, Licht P: Pituitary responsiveness to superfused GnRH in two species of ranid frogs. Gen Comp Endocrinol 1985, 59(2):308-315.

16. Browne RK, Seratt J, Vance C, Kouba A: Hormonal priming, induction of ovulation and in-vitro fertilization of the endangered Wyoming toad (Bufo baxteri). Reprod Biol Endocrinol 2006, 4(34):1-11.

17. Kouba AJ, Delbarco-Trillo J, Vance CK, Milam C, Carr M: A comparison of human chorionic gonadotropin and luteinizing hormone releasing hormone on the induction of spermiation and amplexus in the American toad (Anaxyrus americanus). Reprod Biol Endocrinol 2012, 10(1):59.

18. Browne RK, Li H, Seratt J, Kouba A: Progesterone improves the number and quality of hormone induced Fowler toad (Bufo fowleri) oocytes. Reprod Biol Endocrinol 2006, 1:3-4

19. Sotowska-Brochocka J, Licht P: Effect of infundibular lesions on GnRH and $\mathrm{LH}$ release in the frog, Rana temporaria, during hibernation. Gen Comp Endocrinol 1992, 85(1):43-54.

20. O'Connell LA, Matthews BJ, Ryan MJ, Hofmann HA: Characterization of the dopamine system in the brain of the túngara frog, Physalaemus pustulosus. Brain Behav Evol 2010, 76(3-4):211-225.

21. Nakano M, Hasunuma I, Okada R, Yamamoto K, Kikuyama S, Machida T, Kobayashi T: Molecular cloning of bullfrog D2 dopamine receptor CDNA: Tissue distribution of three isoforms of D2 dopamine receptor mRNA. Gen Comp Endocrinol 2010, 168(1):143-148.

22. Nakano M, Minagawa A, Hasunuma I, Okada R, Tonon MC, Vaudry H, Yamamoto K, Kikuyama S, Machida T, Kobayashi T: D2 Dopamine receptor subtype mediates the inhibitory effect of dopamine on TRH-induced prolactin release from the bullfrog pituitary. Gen Comp Endocrinol 2010, 168(2):287-292.

23. Gonzalez A, Smeets WJAJ: Comparative analysis of dopamine and tyrosine hydroxylase immunoreactivities in the brain of two amphibians, the anuran Rana ridibunda and the urodele Pleurodeles waltlii. J Comp Neurol 1991, 303(3):457-477.

24. Sotowska-Brochocka J, Martynska L, Licht P: Dopaminergic inhibition of gonadotropic release in hibernating frogs, Rana temporaria. Gen Comp Endocrinol 1994, 93(2):192-196.

25. Dufour S, Weltzien FA, Sebert ME, Le Belle N, Vidal B, Vernier P, Pasqualini C: Dopaminergic inhibition of reproduction in teleost fishes: ecophysiological and evolutionary implications. Ann N Y Acad Sci 2005, 1040:9-21.

26. Bezchlibnyk-Butler Z, Jefferies J: Clinical Handbook of Psychotropic Drugs 15th edition. Cambridge, Massacheusetts: Hogrefe and Huber Publishing Company; 2005:348.

27. Trudeau VL, Somoza GM, Natale GS, Pauli B, Wignall J, Jackman P, Doe K, Schueler FW: Hormonal induction of spawning in 4 species of frogs by coinjection with a gonadotropin-releasing hormone agonist and a dopamine antagonist. Reprod Biol Endocrinol 2010, 16:8-36.

28. Echaubard $P$, Little $K$, Pauli B, Lesbarrères D: Context-dependent effects of ranaviral infection on Northern leopard frog life history traits. PLoS One 2010, 5(10):e13723.

29. Melvin SD, Trudeau VL: Growth, development and incidence of deformities in amphibian larvae exposed as embryos to naphthenic acid concentrations detected in the Canadian oil sands region. Environ Pollut 2012, 67:178-83

30. Gosner KL: A simplified table for staging anuran embryos and larvae. Herpetologica 1960, 16:183-190.

31. Omeljaniuk RJ, Shih SH, Peter RE: In-vivo evaluation of dopamine receptor-mediated inhibition of gonadotrophin secretion from the pituitary gland of the goldfish, Carassius auratus. J Endocrinol 1987, 114(3):449-458.

32. Sokolowska M, Peter RE, Nahorniak CS, Chang JP: Seasonal effects of pimozide and des $\mathrm{Gly}^{10}$ [D-Ala ${ }^{6}$ LH-RH ethylamide on gonadotrophin secretion in goldfish. Gen Comp Endocrinol 1985, 57(3):472-479.

33. Trudeau VL: Neuroendocrine regulation of gonadotrophin II release and gonadal growth in the goldfish, Carassius auratus. Rev Reprod 1997, 2(1):55-68. 
34. Lin XW, Lin HR, Peter RE: Seasonal variations in gonadotropin responsiveness, self-priming, and desensitization to $\mathrm{GnRH}$ peptides in the common carp pituitary in vitro. Gen Comp Endocrinol 1994, 93(2):275-287.

35. Fink G: The self-priming effect of LHRH: a unique servomechanism and possible cellular model for memory. Front Neuroendocrinol 1995, 16(2):183-190

36. Silla AJ: Effect of priming injections of luteinizing hormone-releasing hormone on spermiation and ovulation in Günther's toadlet, Pseudophryne guentheri. Reprod Biol Endocrinol 2011, 20:9-68.

37. AmphibiaWeb: Information on amphibian biology and conservation. [web application]. Berkeley, California: AmphibiaWeb. Rana pipiens; 2012. Accessed: Jan 30, 2013.

38. Smalley KN, Nace GW: Vitellogenic cycles in laboratory-maintained females of the leopard frog, Rana pipiens. J Exp Zool 1983, 226(2):211-219.

39. Hogan NS, Duarte P, Wade MG, Lean DR, Trudeau VL: Estrogenic exposure affects metamorphosis and alters sex ratios in the northern leopard frog (Rana pipiens): identifying critically vulnerable periods of development. Gen Comp Endocrinol 2008, 156(3):515-523.

40. Croteau MC, Martyniuk CJ, Trudeau VL, Lean DR: Chronic exposure of Rana pipiens tadpoles to UVB radiation and the estrogenic chemical 4-tert -octylphenol. J Toxicol Environ Health A 2008, 71(2):134-44.

41. Langlois VS, Carew AC, Pauli BD, Wade MG, Cooke GM, Trudeau VL: Low levels of the herbicide atrazine alter sex ratios and reduce metamorphic success in Rana pipiens tadpoles raised in outdoor mesocosms. Environ Health Perspect 2010, 118(4):552-557.

42. Denver RJ: Stress hormones mediate environment-genotype interactions during amphibian development. Gen Comp Endocrinol 2009, 164(1):20-31.

43. Della Togna G, Comizzoli P, Gratwicke B, Trudeau V: Structural and functional characterization of the Panamanian Golden Frog (Atelopus zeteki) spermatozoa - impact of medium osmolality on the motility activation and cell viability: Abstracts, World Congress of Herpetology, University of British Columbia, Vancouver, Canada; 2012:172.

44. Trudeau VL, Schueler FW, Somoza GM, Natale GS, Salgado Costa C, Thoney D, McGinnity D: Hormonal control of spawning in amphibians. Abstracts, World Congress of Herpetology, University of British Columbia, Vancouver, Canada; 2012:730.

doi:10.1186/1477-7827-11-14

Cite this article as: Trudeau et al.: Efficient induction of spawning of Northern leopard frogs (Lithobates pipiens) during and outside the natural breeding season. Reproductive Biology and Endocrinology 2013 11:14.

\section{Submit your next manuscript to BioMed Central and take full advantage of:}

- Convenient online submission

- Thorough peer review

- No space constraints or color figure charges

- Immediate publication on acceptance

- Inclusion in PubMed, CAS, Scopus and Google Scholar

- Research which is freely available for redistribution 